\title{
Evidências de validade de uma versão brasileira do Inventário de Funções do Voluntariado - IFV
}

\author{
Ronaldo Pilati - Universidade de Brasilia, Brasilia, Brasil \\ Maria Alexandra Gaiofatto Hees - Universidade de Brasilia, Brasilia, Brasil
}

\begin{abstract}
Resumo
Entender os motivos que levam o indivíduo a iniciar e manter-se no voluntariado pode contribuir para o recrutamento de novos voluntários e para a retenção no serviço de pessoas já engajadas, pois permite aproximar os objetivos individuais de potenciais voluntários das exigências e benefícios associados às oportunidades concretas de ajuda que o ambiente proporciona. O presente trabalho teve como objetivos adaptar e validar para o Brasil o Inventário de Funções do Voluntariado (IFV) e correlacionar o IFV com a versão reduzida do Questionário de Perfis de Valores (QPV21). Além de corroborar a validade convergente entre estes dois instrumentos, os resultados indicaram que as motivações dos 319 participantes agregaram-se em torno de quatro fatores (valores e entendimento, proteção, carreira e engrandecimento social), replicando parcialmente a estrutura fatorial do instrumento original e confirmando a existência de diferenças culturais nas motivações para o voluntariado. Outras implicações teóricas e empíricas são discutidas.

Palavras-chave: Comportamento pró-social, Motivação, Voluntariado, Abordagem funcionalista, Valores.
\end{abstract}

Evidence of validity of a Brazilian version of the Volunteer Functions Inventory - VFI

\begin{abstract}
Understanding the reasons why people begin and continue to volunteer can contribute to the recruitment of new volunteers and to the retention of those that already engaged, by bringing the individual goals of potential volunteers closer to the requirements and benefits associated with the existing work opportunities. This study aims to adapt and validate the Volunteers Function Inventory (VFI) for Brazil as well as to correlate the VFI with the reduced version of Schwartz's Portrait Value Questionnaire (PVQ21). Results confirmed the convergent validity between these two instruments. In addition, the factor structure of the original instrument was partially replicated, with the motivations of the 319 participants grouping around four factors (values and understanding, protection, career, and social enhancement). These results suggest the existence of cultural differences in the motivations for volunteering. Other empirical and theoretical implications are discussed.

Keywords: Prosocial behavior, Motivation, Volunteer work, Functional approach, Values.
\end{abstract}

Nas sociedades contemporâneas, as instituições do Estado e as forças do mercado revelamse insuficientes para garantir o bem-estar de todos os indivíduos que delas fazem parte. Nesse contexto, ganham importância as iniciativas e ações pró-sociais empreendidas no âmbito da sociedade civil, a exemplo do trabalho voluntário. A importância do voluntariado para proporcionar serviços essenciais para indivíduos, comunidades e sociedade, de modo geral, tem sido amplamente documentada por meio de pesquisas realizadas em vários campos do conhecimento nas últimas décadas. A título de exemplo, o voluntariado já foi relacionado a níveis mais elevados de saúde e otimismo, bem como a uma vida mais longa para aqueles que oferecem assistência a outras pessoas (Snyder \& Omoto, 2008). Neste contexto o presente trabalho tem por objetivo apresentar evidências da validade de construto e convergente de uma versão brasileira do Inventário de Funções do Voluntariado (Clary e colaboradores, 1998), um dos instrumentos mais utilizados para o estudo do voluntariado na literatura de psicologia social.

\footnotetext{
${ }^{1}$ Endereço para correspondência:

Departamento de Psicologia Social e do Trabalho, Universidade de Brasília, Campus Darcy Ribeiro, Asa Norte - 70910-900 - Brasília DF, Brasil.

E-mail: rpilati@gmail.com
}

No Brasil, dados do Instituto Ipsos-Marplan (2005) indicam que 9\% dos brasileiros dedicam-se a algum tipo de atividade voluntária e que o setor tem grande potencial de crescimento. Com o objetivo de regulamentar esse tipo de atividade e contribuir para o seu desenvolvimento, em 1998, foi aprovada a Lei 9.608, que define o voluntariado como

atividade não remunerada, prestada por pessoa física a entidade pública de qualquer natureza, on a instituição privada de fins não-lucrativos, que tenha objetivos civicos, culturais, educacionais, cientificos, recreativos ou de assistência social, inclusive mutualidade.

No âmbito da psicologia social, o voluntariado constitui uma das formas de comportamento prósocial, definido por Batson, Van Lange, Ahmad e Lishner (2003) como qualquer ato que beneficie uma pessoa ou grupo e que seja considerado, por uma parcela significativa da população, como uma ação de benefício e de ajuda. O que distingue o voluntariado de outros tipos de comportamento pró-social é seu caráter planejado, sustentado e contínuo (Snyder \& Omoto, 2008). Ao contrário do comportamento de ajuda espontânea (que se observa, por exemplo, quando um indivíduo ajuda um desconhecido que desmaia na rua), o voluntariado contempla: uma busca livre e ativa por oportunidades de ajuda (Snyder \& Omoto, 2008); uma adequação das habilidades e dos interesses pessoais 
com o tipo de atividade que se pretende exercer; e, por fim, considerações acerca da extensão do envolvimento que se deseja ter e dos gastos de tempo e de energia que o indivíduo pretende alocar para a prática daquele serviço (Clary e colaboradores, 1998).

O trabalho voluntário tem sido amplamente estudado por pesquisadores de diversas áreas desde a década de 1970. No âmbito da psicologia social, atenção especial tem sido dada ao estudo dos antecedentes do voluntariado, dentre os quais se destaca o esforço para identificar os motivos que levam um indivíduo a iniciar e a permanecer nesse tipo de atividade, muitas vezes por longos períodos de tempo. $\mathrm{Na}$ pesquisa do voluntariado, o estudo de características motivacionais, situacionais e de personalidade pode facilitar a identificação de indivíduos com maior propensão para se tornar voluntários. De posse desse conhecimento, torna-se mais fácil estabelecer estratégias eficientes para o recrutamento e a retenção de voluntários. Portanto, muitos pesquisadores adotam uma perspectiva motivacional, com foco no potencial da motivação, para tornar o indivíduo mais disposto à ação, encorajálo a adotar determinadas condutas e torná-lo cada vez mais envolvido com a atividade voluntária, o que, por sua vez, aumenta as chances de que ele permaneça no serviço por mais tempo (Snyder \& Omoto, 2008). Do mesmo modo, muitas das pesquisas nessa área têm sido guiadas pela teoria funcionalista, que enfatiza os propósitos atendidos pela ação e o papel destes no início, na orientação e na sustentação da ação. Com base nesse pressuposto teórico, diversos inventários foram desenvolvidos, ao longo das últimas décadas, seja para aferir motivações de relevância genérica para a ação voluntária, seja para medir motivações para o voluntariado em causas específicas.

O Inventário de Funções do Voluntariado (IFV), de Clary e colaboradores (1998), constitui exemplo de instrumento desenvolvido para a identificação das motivações individuais de natureza genérica para o trabalho voluntário, com base no referencial teórico funcionalista, que se preocupa com a identificação de razões, planos e metas subjacentes ao pensamento, sentimentos e comportamento do indivíduo. Segundo esse referencial teórico, as pessoas assumem atitudes e se engajam em determinados comportamentos como forma de atender a certas funções psicológicas. Desse modo, é comum que indivíduos pratiquem ações que, apesar de semelhantes na aparência, estão a serviço de funções pessoais e sociais muito diferentes (Snyder, 1993). O uso da abordagem funcional para analisar as motivações para o voluntariado revela, portanto, que a prática do mesmo tipo de ajuda pode refletir motivações individuais bastante distintas.

As funções psicológicas atendidas pelo voluntariado têm implicações para o tipo de ajuda, como ela terá início e se será uma atividade duradoura ou não (Clary e colaboradores, 1998). Nesse contexto, ficam evidentes as implicações práticas do tema para o recrutamento de novos voluntários e para a retenção no serviço de pessoas que já estão engajadas. O entendimento das razões que levam o indivíduo a se comprometer com o voluntariado - muitas vezes por longos períodos de tempo - pode contribuir para uma maior aproximação entre os objetivos individuais de potenciais voluntários e as exigências e benefícios associados às oportunidades concretas de ajuda que o ambiente proporciona. De posse desse conhecimento, é possível, por exemplo, criar mensagens para atrair novos voluntários com conteúdo especialmente concebido para ir ao encontro das diferentes motivações individuais para o voluntariado. Este argumento, além de ser corroborado pela pesquisa na área de voluntariado, também encontra ressonância na literatura sobre persuasão em psicologia social. Conforme os achados na pesquisa empírica do Modelo de Probabilidade de Elaboração, que unifica e organiza diferentes teorias de persuasão e influência, o impacto da persuasão de uma mensagem é maior quando ela se dirige de forma direta às motivações do público-alvo (Petty \& Briñol, 2011; Clary e colaboradores, 1998).

Os diversos programas de pesquisa sobre o voluntariado diferem em muitos aspectos, a exemplo do perfil demográfico da amostra utilizada, dos papéis e das causas em que os participantes estão engajados e da abrangência dos objetivos (identificar motivações para o voluntariado de modo geral ou para causas específicas). A despeito dessas diferenças, observam-se muitas semelhanças nos conjuntos de motivações para o voluntariado identificadas no âmbito desses programas (Snyder \& Omoto, 2008). Com base nessas coincidências, Clary e colaboradores (1998) identificaram seis funções psicológicas básicas que seriam atendidas pelo voluntariado, quais sejam: a) a oportunidade de expressar valores altruístas e humanitários (valores); b) a oportunidade de aprender e de colocar em prática conhecimentos e habilidades que a pessoa já possui (entendimento); c) a oportunidade de estar com amigos e de exercer atividades que são valorizadas por pessoas importantes para o indivíduo, ou seja, uma função que reflete a preocupação com normas, recompensas e punições sociais (social); d) benefícios profissionais (carreira); e) a proteção do self de sentimentos negativos, a exemplo de reduzir a culpa por ter mais privilégios do que a maioria das pessoas (proteção); e f) manter um estado 
de espírito positivo e elevada auto-estima (engrandecimento).

Com base nessas funções, foram derivados 30 itens (5 para cada função) que apresentavam razões possíveis para o trabalho voluntário. Pedia-se para o participante indicar, em uma escala Likert de 7 pontos, o grau de importância ou de exatidão que ele atribuía a cada um dos motivos descritos para o voluntariado. $\mathrm{O}$ primeiro de uma série de estudos para validação do instrumento foi realizado com uma amostra de 535 participantes, e análises fatoriais exploratória e confirmatória corroboraram uma estrutura de seis motivações para o voluntariado com cargas fatoriais aceitáveis (de 0,40 a 0,89). Estudos subsequentes atestaram ainda: a) a estabilidade temporal do IFV, com índices de correlação teste-reteste de 0,64 a 0,78 ( $p$ $<0,001$ para todas as motivações); e b) a validade preditiva do instrumento (o IFV constitui um bom preditor, tanto do poder de persuasão de mensagens de recrutamento, quanto da intenção de permanecer por mais tempo na atividade voluntária).

O primeiro objetivo do presente estudo é adaptar e apresentar evidências da validade de construto de uma versão brasileira do Inventário de Funções do Voluntariado para a identificação das motivações individuais para o trabalho voluntário no país, ou seja, evidenciar em que medida o instrumento mede a motivação para o voluntariado como construto teórico (Anastasi \& Urbina, 2000).

Pesquisas na área da psicologia transcultural indicam que as culturas variam consideravelmente no que tange aos significados e às manifestações do voluntariado e de outras formas de ajuda (Levine, Norenzayan \& Philbrick, 2001). Muitas dessas variações guardam relação com a orientação predominantemente individualista ou coletivista das diferentes culturas e regiões do mundo. Nos países de orientação cultural mais individualista, o envolvimento na resolução de problemas da sociedade é visto como uma questão de escolha pessoal e de responsabilidade individual. Nas culturas de orientação mais coletivista, por sua vez, esse envolvimento tende a ser visto como uma obrigação normativa e uma preocupação de natureza coletiva (Snyder \& Omoto, 2008).

Além disso, estudos sugerem a existência de associações entre o grau de individualismo ou coletivismo cultural e vários indicadores de engajamento cívico e cidadania. Nos EUA, por exemplo, os estados da federação que têm orientação mais individualista são também os que apresentam as taxas mais elevadas de voluntariado (Kemmelmeier, Jambor \& Letner, 2006). Esse tipo de evidência vai de encontro à noção de que, em culturas individualistas, os laços sociais são menos valorizados do que em sociedades de orientação mais coletivista, sugerindo que as primeiras podem servir de contexto para que as pessoas se tornem ainda mais envolvidas com os problemas da sociedade (Snyder \& Omoto, 2008).

Outras variáveis têm sido relatadas como antecedentes relevantes das motivações para $\mathrm{O}$ voluntariado na pesquisa em psicologia social transcultural. Van de Vliert, Huang e Levine (2004) apresentaram evidências de que as motivações para o trabalho voluntário variam conforme o nível de renda e a temperatura média da nação. Os autores argumentam que há um efeito significativo do nível de renda e do conforto climático na relação entre motivações altruístas e egoístas para o trabalho voluntário (Van de Vliert e colaboradores, 2004). No caso específico do Brasil, a pesquisa dos autores indicou que os dois tipos de motivações são altos, mas a relação entre as mesmas é baixa.

Considerando as diferenças culturais das motivações para o voluntariado, faz-se necessário o desenvolvimento de estudos de validação do IFV e sua estrutura empírica para diferentes nações. Alguns estudos são encontrados na literatura da área, como o de Dávila e Chacón (2004), que adaptaram e validaram o IFV para a população espanhola, confirmando o modelo multifatorial de motivações para o voluntariado proposto por Clary e colaboradores (1998). O instrumento foi aplicado em 395 voluntários de diversos perfis, resultando em uma estrutura de seis fatores, semelhante àquela proposta no estudo original. Os resultados indicaram que as motivações dos voluntários espanhóis, medidas por meio do IFV, agruparam-se em torno das mesmas seis funções identificadas anteriormente por Clary e colaboradores (1998).

Em um estudo realizado na China (Wu, Wing Lo \& Liu, 2009), o IFV foi aplicado em uma amostra de estudantes universitários. As análises fatoriais realizadas pelos pesquisadores chineses indicaram que as motivações dos participantes daquele país se agregaram em torno de quatro fatores com cargas fatoriais aceitáveis (valores, carreira, social e entendimento). Em outro trabalho, desenvolvido na Itália para identificar as motivações de jovens adultos para o trabalho voluntário, o IFV foi aplicado em uma amostra de 461 voluntários italianos, de 24 a 31 anos, cujas motivações agregaram-se em torno de quatro fatores: carreira, social, valores e proteção (Marta, Guglielmetti \& Pozzi, 2006). No Brasil, foram localizadas publicações de revisões de literatura e poucos estudos visando à identificação de motivações para o trabalho voluntário, com base na abordagem funcionalista (Cavalcante, Souza, Cunha \& Nascimento, 2010; Ferreira, Proença \& Proença, 2008; 
Souza e colaboradores, 2003). Todavia, não há registro de trabalhos realizados com o objetivo específico de construir uma versão brasileira para o Inventário de Funções do Voluntariado.

O segundo objetivo do presente estudo foi avaliar a validade convergente entre o IFV e a versão reduzida do Questionário de Perfis de Valores (QPV) desenvolvido por Schwartz (2005) e validado no Brasil por Campos e Porto (2010), ou seja, mostrar de que maneira o IFV se correlaciona com outro instrumento com o qual deveria se correlacionar em termos teóricos (Anastasi \& Urbina, 2000). $\mathrm{Na}$ literatura sobre o voluntariado, a despeito das já citadas diferenças no número exato de motivações identificadas em diferentes programas de pesquisa, existem semelhanças e motivações que são recorrentes. Uma delas corresponde à expressão de valores (Snyder \& Omoto, 2008). É comum que pessoas se voluntariem como forma de expressar seus valores pessoais e humanitários (Clary e colaboradores, 1998).

Os valores são definidos por Schwartz (1992) como metas e crenças ligadas às emoções, que servem de referencial para a vida do indivíduo, transcendem situações e ações específicas e se ordenam de acordo com a importância relativa atribuída pela pessoa a cada um deles. Existem evidências de que a estrutura circular de valores é quase universal e tem sido usada, entre outras coisas, para explicar a base motivacional das atitudes e do comportamento (Schwartz, 1994). Segundo a teoria dos valores (Schwartz, 1992; 2005; 2006), qualquer atitude ou comportamento tende a ser reflexo de um compromisso ou equilibrio que o indivíduo estabelece entre valores conflitantes, relevantes em um determinado contexto (o que facilita sua ativação).

O modelo dos valores de Schwartz (1992) descreve uma estrutura circular de relações dinâmicas entre dez valores de ordem inferior, que diferem de acordo com a meta ou motivação que eles expressam, quais sejam: autodeterminação (pensamento e ação independentes; escolha, criação e exploração); estimulação (excitação, novidade e desafios); hedonismo (prazer e gratificação sensual); realização (sucesso pessoal pela demonstração de competência, em conformidade com padrões sociais); poder (status social e prestígio, controle ou domínio sobre outras pessoas e recursos); segurança (harmonia e estabilidade na sociedade, nas relações e em si mesmo); conformidade (restrição de ações, inclinações e impulsos com potencial para prejudicar os outros e violar normas ou expectativas sociais); tradição (respeito, comprometimento e aceitação de costumes e ideias que a cultura ou religião tradicional proporciona ao self); benevolência (preservação e fortalecimento do bem-estar do grupo de pertencimento); e universalismo (compreensão, gratidão e proteção do bem-estar da natureza e do ser humano em geral).

Nessa estrutura circular, tornam-se evidentes as relações de conflitos e de congruência entre os valores descritos (Schwartz, 1992). Cada um deles está representado em uma fatia do círculo, exceto pela tradição e pela conformidade, que são representadas em um mesmo pedaço, por compartilharem o mesmo objetivo motivacional de subordinação do self (subordinação a outras pessoas, no caso da conformidade, e a objetos mais abstratos, como religião, costumes e ideias, no caso da tradição). Quanto mais próximos os valores no sentido do círculo, mais compatibilidade há entre eles e suas motivações subjacentes. Quanto mais distantes e opostos, mais antagônicos e conflitantes são os valores e os objetivos motivacionais que eles expressam. De acordo com o mesmo modelo (Schwartz, 1992), a estrutura integrada desses valores de ordem inferior pode ser resumida em duas dimensões ortogonais de ordem superior: 1) autotranscendência (abrangendo os valores universalismo e benevolência), que se opõe a autopromoção (contemplando os valores poder, realização e hedonismo); e 2) abertura à mudança (agrupando hedonismo, estimulação e autodeterminação), que se opõe a conservação (abrangendo tradição, conformidade e segurança). O valor hedonismo compartilha elementos tanto com abertura à mudança quanto com autopromoção.

Por intermédio de análise de correlação entre o Inventário das Funções do Voluntariado e a versão reduzida do Questionário de Perfis de Valores, esperase, por exemplo, que a dimensão de autotranscendência do PQV correlacione-se positivamente com as dimensões de valores e entendimento do IFV e negativamente com a dimensão de autopromoção do instrumento de Schwartz. Esta última, por sua vez, poderia guardar relação positiva com as dimensões de carreira e engrandecimento do self do IFV. Do mesmo modo, é possível que a dimensão de abertura a mudanças do PQV apresente correlação positiva com as dimensões de entendimento e carreira e negativa com as dimensões de respeito às normas (social) e proteção do self do IFV. No que tange a essas últimas, são esperadas correlações positivas com a dimensão de conservação do modelo de Schwartz.

\section{Método}

\section{Participantes}

Participaram do presente estudo 319 voluntários $(65,8 \%$ do sexo feminino), de diversas regiões do Brasil, com idade média de 37,69 anos 
( $D P=13,61)$, renda mensal média de $\mathrm{R} \$ 8.353,59$ $(D P=8.236,54)$ e tempo médio de voluntariado de 6,93 anos $(D P=7,05)$. A maioria dos participantes $(84,6 \%)$ tinha curso superior, $8,5 \%$ tinha completado pelo menos o ensino médio e $78,4 \%$ praticava alguma religião, com dedicação média de $2,42(D P=1,38)$ horas semanais a atividades de natureza religiosa.

\section{Instrumentos}

Para atingir o objetivo proposto, foi elaborado e aplicado um instrumento para aferição das funções do voluntariado. Optou-se por não se realizar uma tradução direta do IFV em língua inglesa, mas sim a construção de itens baseados rigorosamente na sua dimensão teórica. Inicialmente foram realizadas entrevistas com voluntários visando à elaboração dos itens. As entrevistas foram transcritas e os dados categorizados conforme as seis dimensões propostas por Clary e colaboradores (1998). Essa análise resultou na elaboração de 58 itens. Estes foram submetidos à análise semântica e de juízes, especialistas na elaboração de medidas psicométricas, o que resultou na permanência de 24 itens divididos equitativamente entre as seis dimensões. Estes foram associados a uma escala Likert de frequência e aplicados conjuntamente com PQV21, instrumento para avaliação das dimensões de valores do modelo de Schwartz (2005), composto por 21 itens que avaliam as 10 dimensões de primeira ordem do modelo teórico e que possui evidências de validade para o Brasil apresentada por Campos e Porto (2010). Na versão brasileira, o PQV21 mantém as duas dimensões de segunda ordem do modelo circular de Schwartz (2005).

\section{Procedimentos de coleta e Análise de dados}

A coleta de dados foi realizada via internet, por meio de software para coleta on-line de dados EFS Survey (www.unipark.com), e teve duração de quatro meses. O convite para participar do estudo foi feito via correio eletrônico para uma lista inicial de 250 destinatários. $\mathrm{Na}$ mensagem de convite era feita solicitação para que os destinatários repassassem para suas listas de contatos, o que nos impede de conhecer o número real de pessoas para as quais o convite de participação chegou. O sistema de coleta estava programado para registrar respostas apenas dos participantes que concluíssem todo o questionário, evitando questionários preenchidos de forma incompleta.

Para a aferição da estrutura do instrumento, foi realizada análise fatorial pelo método Principal-axis factoring (PAF), com rotação oblíqua promax. Foram realizadas, ainda, uma ANOVA para avaliar a relação entre os fatores resultantes e os dados demográficos, bem como uma análise de correlação bivariada entre o Inventário de Funções do Voluntariado e o PQV21 (Campos \& Porto, 2010) para a aferição da validade convergente.

\section{Resultados}

A matriz de correlações era fatorável $\left(\mathrm{KMO}=0,86\right.$ e Bartlet $\left.\chi^{2}(276)=3998,57 ; \mathrm{p}<0,001\right)$ e a análise do gráfico de sedimentação (Figura 1) indicou a extração entre quatro e sete fatores. Optou-se pela extração de quatro fatores em uma análise de fatoração dos eixos principais com rotação promax. Como pode ser observado na Tabela 1, quatro fatores da estrutura original da escala se agregaram em duas dimensões. Itens da dimensão social agregaram-se aos da dimensão engrandecimento e os do fator valores ficaram agregados aos de entendimento. Os fatores de proteção e carreira formaram agrupamentos independentes. Os quatro fatores foram assim nomeados: o primeiro refere-se ao engrandecimento social; o segundo a valores e entendimento; o terceiro a proteção; e o quarto a carreira. Esta estrutura possui indicadores aceitáveis de confiabilidade e, apesar de não replicar a estrutura de seis fatores do instrumento original, a solução guarda similaridade teórica que permite comparações e testes diferenciados de hipótese. A matriz de correlação entre os fatores indica que o fator engrandecimento social está associado a valores e entendimento $(r=0,61 ; p<0,001)$, a Proteção $(r=0,52$; $\mathrm{p}<0,001)$ e a Carreira $(\mathrm{r}=0,11 ; \mathrm{p}<0,05)$. Também se observa correlação entre Valores e Entendimento, e Proteção $(r=0,46 ; p<0,001)$. 


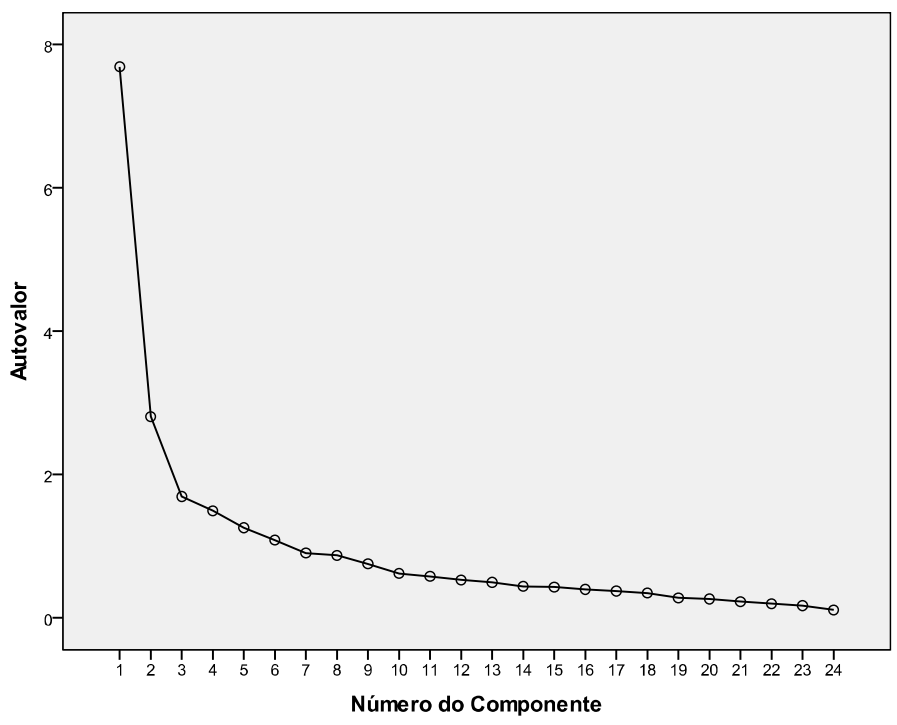

Figura 1. Gráfico de sedimentação com os autovalores e números de componentes para o IFV

Como forma de testar a capacidade discriminativa do instrumento a partir da estrutura da Tabela 1, foram realizadas análises de comparação dos dados demográficos. Observou-se que indivíduos que possuem amigos voluntários têm escore mais alto no fator engrandecimento social $[F(1,294)=6,20 ; p=0,01]$. Aqueles que relataram que já realizaram outra atividade voluntária possuem escore mais elevado no fator valores e entendimento $[F(1,294)=5,10 ; p=0,03]$. Já os participantes que informam praticar uma religião obtiveram escores significativamente mais elevados nos fatores engrandecimento social $[\mathrm{F}(1,294)=16,55$; $\mathrm{p}<0,001]$, valores e entendimento $[\mathrm{F}(1,294)=22,16$; $\mathrm{p}<0,001]$ e proteção $[\mathrm{F}(1,294)=22,46 ; \mathrm{p}<0,001]$. Também foi observado que participantes que realizam atividade voluntária ligada à religião obtiveram escores mais elevados nos fatores valores e entendimento $[\mathrm{F}(1$, 236) $=3,87 ; \quad \mathrm{p}=0,05] \quad$ e carreira $\quad[\mathrm{F}(1,236)=8,35$; $\mathrm{p}=0,004]$.

Foram observadas, ainda, associações significativas entre a importância da religião e os fatores engrandecimento social $(\mathrm{r}=0,21 ; \mathrm{p}=0,001)$, valores e entendimento $(\mathrm{r}=0,22 ; \mathrm{p}=0,001)$ e proteção $(\mathrm{r}=0,20 ; \mathrm{p}=0,002)$. Já o fator carreira correlacionou-se de forma negativa e significativa com idade $(r=-0,33$; $\mathrm{p}<0,001)$, renda $(\mathrm{r}=-0,18 ; \mathrm{p}=0,002)$, tempo dedicado ao trabalho voluntário $(\mathrm{r}=-0,17 ; \mathrm{p}=0,002)$ e quantidade de horas semanais dedicadas à religião $(\mathrm{r}=-0,17$; $\mathrm{p}=0,01)$.

Com o intuito de testar a validade convergente desta versão do IFV e valores pessoais, foi realizada uma análise de correlação dos fatores com as quatro dimensões de segunda ordem da versão reduzida do instrumento PQV de valores. Ressalta-se que foi aplicado o procedimento de controle para o uso da escala de valores, conforme recomendações (Schwartz, 2005). Os resultados indicam que maior endosso de autotranscendência está associado a escores maiores de valores e entendimento $(r=0,28 ; p<0,001)$ e menores de carreira $(r=-0,15 ; p=0,007)$. Já a dimensão polar oposta autopromoção, está associada a escores menores de valores e entendimento $(\mathrm{r}=-0,22 ; \mathrm{p}<0,001)$ e maiores de carreira $(r=0,25 ; \mathrm{p}<0,001)$. A dimensão de abertura à mudança tem associação positiva com proteção $(\mathrm{r}=0,12 ; \mathrm{p}=0,04)$ e negativa com carreira $(\mathrm{r}=$ $0,12 ; \mathrm{p}=0,04)$. Já a dimensão de conservação tem relação negativa com proteção $(\mathrm{r}=-0,18 ; \mathrm{p}=0,001)$ e positiva com carreira $(\mathrm{r}=0,17 ; \mathrm{p}=0,002)$. 
Tabela 1. Itens com cargas fatoriais e comunalidades organizados por cada um dos fatores da solução fatorial

\begin{tabular}{|c|c|c|c|c|c|}
\hline & $\begin{array}{c}\text { Social/ } \\
\text { Engrandecimento }\end{array}$ & $\begin{array}{c}\text { Valores/ } \\
\text { Entendimento }\end{array}$ & Proteção & Carreira & $\mathrm{h}^{2}$ \\
\hline Alfa de Cronbach & 0,85 & 0,84 & 0,72 & 0,82 & \\
\hline $\begin{array}{l}\text { O voluntariado me permite fazer bons } \\
\text { amigos. }\end{array}$ & 0,87 & & & & 0,64 \\
\hline $\begin{array}{l}\text { O voluntariado me permite criar } \\
\text { vínculos afetivos com outros } \\
\text { voluntários. }\end{array}$ & 0,76 & & & & 0,57 \\
\hline $\begin{array}{l}\text { Trabalhar voluntariamente aumenta } \\
\text { minha autoconfiança. }\end{array}$ & 0,61 & & & & 0,68 \\
\hline $\begin{array}{l}\text { Trabalhar como voluntário(a) } \\
\text { aumenta minha autoestima. }\end{array}$ & 0,59 & & & & 0,63 \\
\hline $\begin{array}{l}\text { Participando do trabalho voluntário } \\
\text { aprendo a lidar com situações } \\
\text { diferentes. }\end{array}$ & 0,52 & & & & 0,42 \\
\hline $\begin{array}{l}\text { As pessoas próximas de mim } \\
\text { valorizam o trabalho voluntário. }\end{array}$ & 0,44 & & & & 0,36 \\
\hline $\begin{array}{l}\text { Meus amigos veem o voluntariado } \\
\text { como algo importante. }\end{array}$ & 0,43 & & & & 0,38 \\
\hline $\begin{array}{l}\text { Gosto de ser prestativo para a } \\
\text { sociedade. }\end{array}$ & & 0,77 & & & 0,54 \\
\hline $\begin{array}{l}\text { Por meio do voluntariado eu posso } \\
\text { ajudar a melhorar o mundo. }\end{array}$ & & 0,67 & & & 0,50 \\
\hline $\begin{array}{l}\text { Fazer algo de bom a outras pessoas é } \\
\text { importante para mim. }\end{array}$ & & 0,62 & & & 0,45 \\
\hline $\begin{array}{l}\text { O voluntariado me ajuda a } \\
\text { compreender como o mundo poderia } \\
\text { ser melhor. }\end{array}$ & & 0,61 & & & 0,50 \\
\hline $\begin{array}{l}\text { O trabalho voluntário é uma boa } \\
\text { forma de fazer justiça. }\end{array}$ & & 0,46 & & & 0,32 \\
\hline $\begin{array}{l}\text { Eu aprendo com a carência (afetiva, } \\
\text { financeira, psicológica, etc.) do outro. }\end{array}$ & & 0,42 & & & 0,41 \\
\hline $\begin{array}{l}\text { No voluntariado eu perco } \\
\text { preconceitos. }\end{array}$ & & 0,39 & & & 0,34 \\
\hline $\begin{array}{l}\text { Eu me sinto ativo graças ao trabalho } \\
\text { voluntário. }\end{array}$ & & 0,33 & & & 0,35 \\
\hline $\begin{array}{l}\text { Trabalhar voluntariamente faz eu me } \\
\text { sentir bem comigo. }\end{array}$ & & 0,32 & & & 0,49 \\
\hline $\begin{array}{l}\text { O voluntariado me auxilia na } \\
\text { resolução dos meus próprios } \\
\text { problemas. }\end{array}$ & & & 0,79 & & 0,70 \\
\hline $\begin{array}{l}\text { O trabalho voluntário me ajuda a } \\
\text { entender os problemas da minha vida. }\end{array}$ & & & 0,65 & & 0,46 \\
\hline $\begin{array}{l}\text { Trabalhar voluntariamente é uma } \\
\text { forma de esquecer meus problemas. }\end{array}$ & & & 0,50 & & 0,31 \\
\hline $\begin{array}{l}\text { O trabalho voluntário diminui a } \\
\text { minha culpa por ser mais afortunado } \\
\text { que muitos. }\end{array}$ & & & 0,45 & & 0,26 \\
\hline $\begin{array}{l}\text { O trabalho voluntário funciona como } \\
\text { uma porta para a minha carreira } \\
\text { profissional. }\end{array}$ & & & & 0,88 & 0,78 \\
\hline $\begin{array}{l}\text { Como voluntário eu faço contatos } \\
\text { para trabalhos remunerados. }\end{array}$ & & & & 0,79 & 0,62 \\
\hline $\begin{array}{l}\text { O voluntariado auxilia na minha } \\
\text { capacitação para um emprego. }\end{array}$ & & & & 0,78 & 0,65 \\
\hline $\begin{array}{l}\text { Como voluntário eu aprendo coisas } \\
\text { úteis para minha carreira. }\end{array}$ & & & & 0,44 & 0,44 \\
\hline
\end{tabular}




\section{Discussão}

O presente trabalho teve como objetivo apresentar evidências de validade de uma versão em português do Inventário de Funções do Voluntariado. Este objetivo foi alcançado, e uma versão do instrumento foi produzida para o uso em pesquisa e outras aplicações práticas.

A estrutura de seis fatores do IFV não foi replicada, mas foi encontrada uma estrutura fatorial equivalente e que guarda as principais características teóricas da proposição de Clary e colaboradores (1998). Dois fatores emergiram conforme a proposta original, pois agregaram itens unicamente pertencentes às dimensões de carreira e proteção. Já as dimensões de valores e entendimento formaram um fator único. Esse resultado pode ser interpretado como a oportunidade de colocar em prática conhecimento e habilidades como algo coerente e altamente relacionado à expressão de valores altruístas. Já as dimensões de social e engrandencimento agregaram-se em um único fator. $\mathrm{Na}$ esteira da mesma interpretação, isso pode significar que a motivação de participação na atividade voluntária como uma forma de manter relações sociais também expressa uma visão positiva de si mesmo, evidenciando possuir relações sociais e ser apreciado como um meio para manter autoestima positiva.

Estudos de adaptação do IFV para outras culturas também não corroboraram a mesma estrutura relatada por Clary e colaboradores (1998), como foi o caso da versão chinesa (Wu, Wing Lo \& Liu, 2009) e italiana do instrumento (Marta, Guglielmetti \& Pozzi, 2006), que não obtiveram as seis dimensões preconizadas. Resultados como esses indicam que existem variações para a estrutura inicialmente proposta que podem ser devidas e aspectos culturais da expressão das motivações para o voluntariado. Tais elementos culturais podem desempenhar um papel relevante em arranjos diferenciados das motivações do voluntariado em cada nação.

O estudo de Van de Vliert e colaboradores (2004) fornece indícios da causa dessa diferença na estrutura do IFV. Conforme argumentado pelos autores, a relação entre motivações altruístas e egoístas do voluntariado é diferente e influenciada pelo conforto termoclimático da nação e sua renda per capita. Segundo o estudo, as nações ricas e de clima desconfortável, seja frio ou quente, possuem relação positiva entre os dois tipos de motivação. No estudo, o Brasil é considerado como um país de renda baixa e clima desconfortavelmente quente. Ainda que os dois tipos de motivação sejam altos para os brasileiros, a relação entre as motivações é baixa. A estrutura encontrada na presente amostra traz indícios de que motivações mais altruístas, expressas pelo fator valores e entendimento, não possuem relação com o fator carreira, o que corrobora os achados de Van de Vliert e colaboradores (2004). Cabe ressaltar que a estratégia de mensuração das motivações de Van de Vliert e colaboradores foi diferente da empregada no presente estudo, mas a mesma ortogonalidade entre algumas das dimensões foi aqui observada.

Em relação aos indicadores de validade discriminante da escala, várias evidências corroboram este elemento. A evidência de que os mais jovens, com menos tempo de dedicação e menor renda endossam mais o fator carreira é coerente com a noção de que o voluntariado constitui-se como uma forma de incrementar a vida profissional. Já a evidência de que quem possui amigos voluntários endossa mais o fator engrandecimento social indica que o voluntariado é uma forma de aumentar e de manter a rede de relações sociais. Também há indícios de validade quando aqueles que relatam maior envolvimento com a atividade voluntária endossam mais o fator de valores e entendimento. Resultados como esses indicam que a estrutura fatorial diferencia perfis de voluntários, o que é coerente com uma noção teórica de que as motivações para o voluntariado divergem entre os trabalhadores voluntários. No caso específico deste estudo, fica evidenciado que mesmo a estrutura de quatro fatores é capaz de discriminar entre os tipos de voluntários.

O teste de validade convergente com o modelo de valores de Schwartz também foi corroborado. As predições esperadas foram observadas, pois valores de autotranscendência foram significativamente correlacionados com as motivações altruístas do IFV (i.e., valores e entendimento), e os valores de autopromoção foram associados a motivações de metas pessoais do IFV (i.e., carreira). Ainda que os efeitos das correlações não tenham sido elevados, estas foram na direção esperada. A magnitude reduzida das correlações também pode ser efeito da estrutura empírica encontrada, que efetiva a mescla de motivações que estavam previstas como independentes no estudo original do IFV. Essas evidências reforçam indícios de validade da versão brasileira do IFV, considerando a coerência entre motivações para o voluntariado e os valores de Schwartz.

Considera-se que a versão apresentada neste trabalho do IFV é um instrumento que pode ser utilizado para pesquisa e gestão de organizações de voluntários no Brasil. De forma geral, o modelo do IFV recebe corroboração parcial, e a diferença na estrutura original já era esperada, uma vez que a pesquisa transcultural mostra que há diferenças significativas nas motivações dos voluntários em 
relação aos valores culturais (i.e., coletivismo), da renda da nação e do conforto climático (Van de Vliert \& colaboradores, 2004). Uma limitação do presente estudo refere-se ao caráter pouco diversificado da amostra utilizada, composta em grande medida por pessoas que praticam o voluntariado no âmbito de suas respectivas religiões. A esse respeito, seria desejável que trabalhos subsequentes contemplassem uma amostra de participantes com perfil mais diversificado.

A título de contribuição para a pesquisa transcultural das motivações do voluntariado, este trabalho produz uma versão do IFV que pode ser utilizada para comparações culturais, além dos resultados aqui apresentados constituírem mais uma peça de evidência sobre a diferença das motivações entre as culturas. O campo continua aberto para futuras investigações comparativas sobre as motivações do voluntariado, e segue como demanda de pesquisa para a área o cumprimento de uma agenda de pesquisa sobre o voluntariado no Brasil por meio do teste de modelos de variáveis antecedentes e consequentes, como forma de melhor compreendermos este fenômeno em nossa cultura.

\section{Referências}

Anastasi, A. \& Urbina, S. (2000). Testagem psicologica (7 ed.). Porto Alegre: Artmed.

Batson, C. D., Van Lange, P. A., Ahmad, N. \& Lishner, D. L. (2003). Altruism and helping behavior. Em M. Hogg \& J. Cooper. The SAGE handbook of social psychology (Vol. 1, pp. 279-295). London: SAGE.

Campos, C. B. \& Porto, J. B. (2010). Escala de valores pessoais: Validação da versão reduzida em amostra de trabalhadores brasileiros. Psico, 4(2), 208-213.

Cavalcante, C. E., Souza, W. J., Cunha, A. S., \& Nascimento, M. A. (2010). Comportamento organizacional no trabalho voluntário: motivos, perfis e correlações na Pastoral da Criança. Estudos do CEPE, 31, 97-132.

Clary, E. G., Snyder, M., Ridge, R. D., Copeland, J., Stukas, A. A., Haugen, J. \& Miene, P. (1998). Understanding and assessing the motivations of volunteers: a functional approach. Journal of Personality and Social Psychology, 74(3), 1516-1530.

Dávila, M. C. \& Chacón, F. (2004). Adaptación del inventario de funciones del voluntariado al voluntariado español. Trabalho apresentado no II Congreso Hispanoportugués, Lisboa.
Ferreira, M., Proença, T. \& Proença, J. F. (2008). As motivações no trabalho voluntário. Revista Portuguesa e Brasileira de Gestão, 7(3), 43-53.

Ipsos-Marplan. (2005). O perfil do voluntariado. Release de pesquisa. Disponível em: www.ipsos.com.br/imagens/release/5mar2005.do c

Kemmelmeier, M., Jambor, E. E. \& Letner, J. (2006). Individualism and good works: cultural variation in giving and volunteering across de United States. Journal of Cross Cultural Psychology, 37, 327-344.

Lei n. 9.608, de 18 de fevereiro de 1998 (1998). Dispõe sobre o serviço voluntário e dá outras providências. Brasillia, DF. Obtido em 3 de março de 2011 de http://www.planalto.gov.br/ccivil_03/Leis/L960 8.htm.

Levine, R. V., Norenzayan, A. \& Philbrick, K. (2001). Cross-cultural differences in helping strangers. Journal of Cross-Cultural Psychology, 32, 543-560.

Marta, E., Guglielmetti, C. \& Pozzi, M. (2006). Volunteerism during young adulthood: an Italian investigation into motivational patterns. Voluntas, 17(3), 221-232.

Petty, R. E. \& Briñol, E. (2011). The elaboration likelihood model. Em P. A. Van Lange, A. W. Kruglanski \& E. T. Higgins (Eds.). Handbook of theories of social psychology (Vol. 1, pp. 224-245). London: Sage.

Schwartz, S. H. (1992). Universals in the content and structure of values: theoretical advances and empirical tests in 20 countries. Advances in Experimental Social Psychology, 25, 1-65.

Schwartz, S. H. (1994). Are there universal aspects in the structure and contents of human values? Journal of Social Issues, 50, 19-45.

Schwartz, S. H. (2005). Basic human values: their content and structure across countries. Em A. Tamayo \& J. B. Porto (Orgs.). Valores e comportamento nas organizações (pp. 21-55). Petrópolis: Vozes.

Schwartz, S. H. (2006). Les valeurs de base de la personne: théorie, mesures et applications. Revue Française de Sociologie, 42, 249-288.

Snyder, M. (1993). Basic research and practical problems: the promise of a "functional" personality and social psychology. Personality and Social Psychology Bulletin, 19, 251-264. 
Snyder, M. \& Omoto, A. M. (2008). Volunteerism: social issues perspectives and social policy implications. Social Issues and Policy Review, 2(1), 136.

Souza, C. B., Bacalhau, M. N., Moura, M., Volpi, J. H., Marques, S. \& Rodrigues, M. G. (2003). Aspectos da motivação para o trabalho voluntário com doentes oncológicos: um estudo colaborativo entre Brasil e Portugal. Psicologia, Saúde \& Doenças, 4(3), 267-276.
Van de Vliert, E., Huang, X. \& Levine, R. V. (2004). National wealth and thermal climate as predictors of motives for volunteer work. Journal of CrossCultural Psychology, 35, 62-73.

Wu, J., Wing Lo, T. \& Liu, E. S. (2009). Psychometric properties of the volunteer functions inventory with Chinese students. Journal of Community Psychology, 37(6), 769-780.

Recebido em 01/09/2011 Reformulado em 10/10/2011 Aprovado em 01/11/2011

Sobre os autores:

Ronaldo Pilati possui Doutorado em Psicologia pela Universidade de Brasília. É professor adjunto do Departamento de Psicologia Social e do Trabalho (PST) e do Programa de Pós-Graduação em Psicologia Social, do Trabalho e das Organizações (PSTO) da UnB.

Maria Alexandra Gaiofatto Hees possui graduação em Relações Internacionais pela Universidade de Brasília e é aluna de graduação em Psicologia na Universidade de Brasília. 